\section{Defining the first preventive conservation guidelines for hand-painted magic lantern glass slides}

\section{Definição das primeiras diretrizes de conservação preventiva para diapositivos de vidro de lanterna mágica pintados à mão}

ÂNGELA SANTOS ${ }^{1,2, ; *}$ (i) BEATRIZ RODRIGUES ${ }^{1}$ VANESSA OTERO ${ }^{1,2}$ (1) MÁRCIA VILARIGUES ${ }^{1,2, \%}$ (1)

1. Department of Conservation and Restoration, NOVA School of Sciences and Technology (FCT NOVA), Caparica, Portugal 2. Research Unit VICARTE - Glass and Ceramic for the Arts, NOVA School of Sciences and Technology (FCT NOVA), Caparica, Portugal *aba.santos@campus.fct.unl.pt (AS); mgv@fct.unl.pt (MV)

\section{KEYWORDS}

Magic Lantern glass slides Painting materials

Glass

Preventive conservation Portuguese Cinematheque - Museum of Cinema National Museum of Natural History and Science (MUHNAC)

\section{PALAVRAS-CHAVE}

Diapositivos de vidro de

Lanterna Mágica

Materiais de pintura

Vidro

Conservação preventiva

Cinemateca Portuguesa Museu do Cinema

Museu Nacional de Histórica Natural e da Ciência (MUHNAC) 


\section{Introduction}

The magic lantern was invented in the mid-seventeenth century as the first optical instrument for the projection of magnified images for a collective audience. By combining the visual projection of moving animated images with audio performances that included sounds, melodies, and recitation of texts, it became one of the most popular instruments of the eighteenth and nineteenth centuries $[1-3]$. In the early twentieth century, it gradually fell into disuse with the emergence of cinema and its substitution by overhead projectors that used transparent acetate sheets, or slides, in educational institutions $[2,4]$. The magic lantern was a common device in homes, theatres, churches, and academic institutions, and it was mainly used for knowledge dissemination, to illustrate lectures in academies, and provide impactful shows for the entertainment of children and adults. Discursive genres like tales, romance, religion, phantasmagories, and burlesque were initially represented on the slides. In the nineteenth century, the diversity of subjects increased and included sequences of dramas, topical themes, adventure scenes, geographic themes, historical episodes, educational and pedagogical subjects, as well as news and advertisement [4-7].

The projected images were depicted on glass supports, commonly referred to as magic lantern slides, with distinct techniques throughout time. Hand painting was the first technique to be used and it persisted until the end of the nineteenth century $[3,6]$. Methods for printing on glass appeared in the first half of the nineteenth century, and they were used either to print the entire composition with colours (e.g. chromolithography) or only the outlines which were then coloured by hand [3, 6]. For the latter, black paint mixed with varnish or fired black enamel was used [6]. During the second half of the nineteenth century, photographic processes were developed, sometimes combined with hand-colouring $[3,6]$. According to the written historical sources, painting on glass for magic lantern slides was understood to require the mastery of a precise skill, since the projections magnified all details and imperfections, and colour transparency was a constant concern. Watercolours were said to be preferred to oil colours for the depiction of the images, but the two could also be combined with excellent results. Varnishes would also be mixed with the paints to give them more transparency or applied on top for protection $[6,8]$.

Collections of glass slides held in museums, private and educational collections, libraries and archives have been increasingly studied to unveil the role and relevance of the magic lantern in historical, social, and cultural contexts around the world $[7,9]$. Over the years, several projects have contributed to the interpretation, digital preservation, and classification of slide collections and made them more available to scholars and the general public (e.g. "A Million Pictures: Magic Lantern Slide Heritage as Artefacts in the
Common European History of Learning" (AMP), 2015-2018) $[7,10]$. Even though institutions frequently have hundreds to thousands of slides, they are rarely able to prioritise their time and personnel to these collections, since there is a lack of specialised knowledge about curating and cataloguing of magic lantern slides [11]. In addition, the frequent lack of high-resolution photographs, inventory, and the necessity of combining information from multiple sources (e.g. catalogues, trade press, lecture material and readings) to adequately describe and catalogue lantern slides, constitutes some of the main obstacles for their study and preservation [7, 11-12]. Furthermore, only preventive and interventive conservation guidelines for photographic glass slides are currently available, and no specific guidelines for the preservation of hand-painted magic lantern slides could be found by the authors [13-15]. The study of the materials and techniques applied in the production of hand-painted magic lantern glass slides remains an understudied field, with only six studies on material characterisation published until this moment, three of them resulting from the ongoing investigation within the author's project Lanterna Magica, described below [12, 16-20].

\section{Research Context}

The present work is part of the project "Lanterna Magica Technology and Preservation of Painted Glass Slides for Projection with Magic Lanterns" [21]. This investigation is starting to unravel the processes behind the production of these detailed, transparent, and vividly colourful paintings, by studying Portuguese collections of handpainted magic lantern slides for the first time. This project aims to simultaneously analyse historical written sources on methods and materials used to produce hand-painted glass slides and those hand-painted over printed outlines, characterise both glass support and painting materials applied on historical slides and reconstruct nineteenthcentury painting materials to study their degradation mechanisms, possibly accelerated during the projections. With this research, the authors not only hope to assign production periods and producers, but also further our understanding on the key factors and mechanisms that lead to the degradation of historical hand-painted glass slides and assess their conservation state with more precision. Ultimately, the in-depth study of their original production methods and artists' materials will contribute to further develop both preventive and interventive conservation guidelines for existing collections.

During a previous phase of the project, 20 exclusively hand-painted magic lantern slides from the Portuguese Cinematheque - Museum of Cinema (CP) and Nacional Museum of Natural History and Science of the University of Lisbon (MUHNAC), Portugal, have been studied through a multi-analytical approach [12, 16-17]. The initial results of the material characterisation, carried out within this project, have revealed a correlation between the written historical 

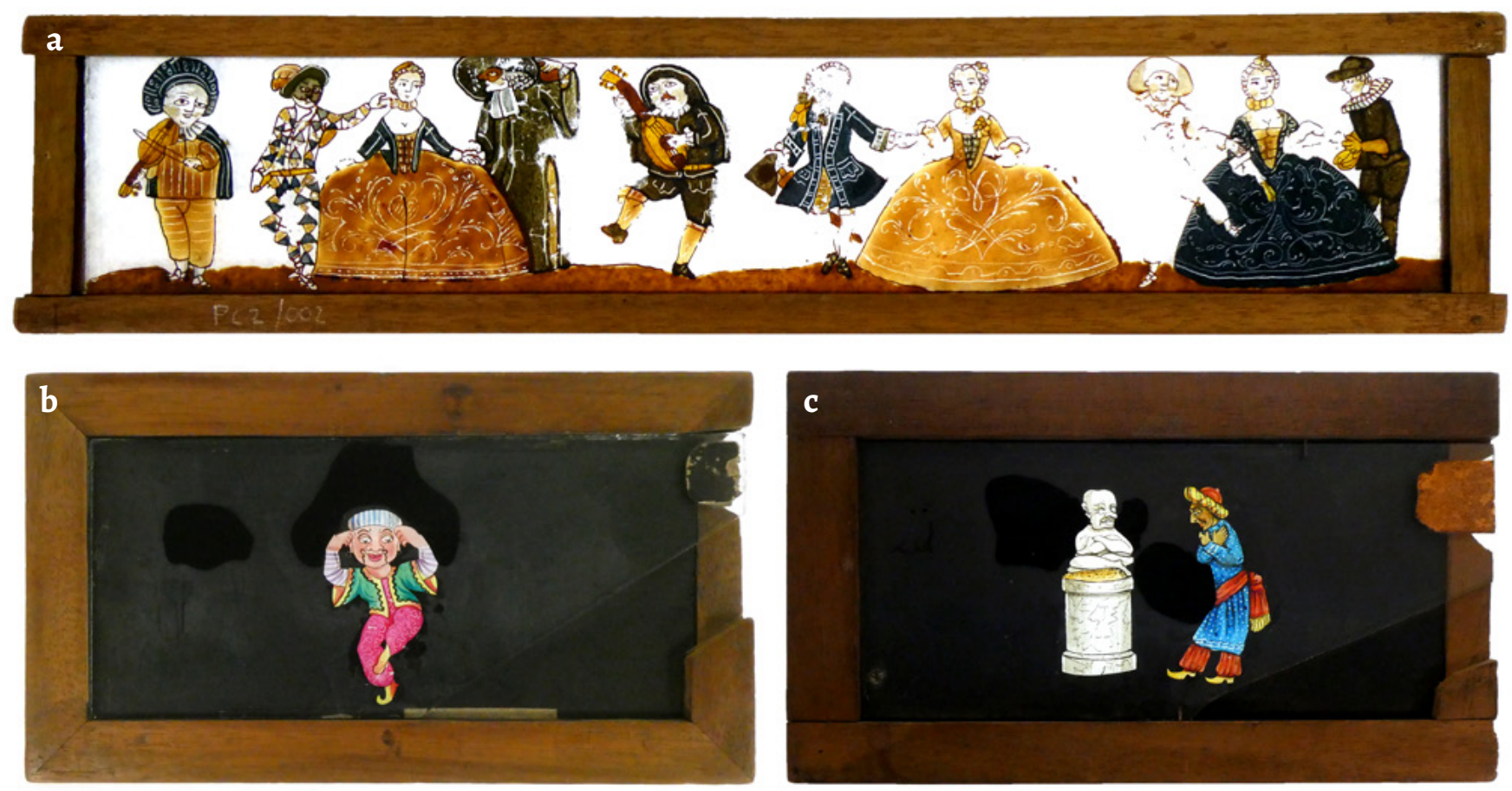

Figure 1. Examples of studied exclusively hand-painted magic lantern glass slides, from the Portuguese collections: $a$ ) panorama slide from 18th century Italy, from CP, 8.6 × $39.7 \mathrm{~cm}$ (inv. CP_PCo02/002); b) single slipping slide from 19th century England, from CP, $10 \times 17 \mathrm{~cm}$ (inv. CP_PC3302/009); c) single slipping slide from 19th century England, from MUHNAC, 10 x $17.5 \mathrm{~cm}$ (inv. ULISBOA-MUHNAC-UL000067) (photo credits: Ângela Santos) [12].

sources and slides from the same period. Of the 20 slides studied, 11 are stylistically assigned to eighteenth-century Italy and nine are assigned to the nineteenth century England (Figure 1).

Two different types of glass supports were identified. The set of eighteenth-century slides stylistically assigned to Italy had a potassium-rich glass support similar to the white or chalk glass produced in Central Europe (with $\mathrm{Na}_{2} \mathrm{O}+\mathrm{MgO}<1$ wt. \%, $\mathrm{K}_{2} \mathrm{O}$ from 12 to 19 wt. \%, and $\mathrm{CaO}$ from 7 to 9 wt. \%) $[12,16,22]$. The nineteenth-century slides, attributed to England, were produced with a sodalime-silicate glass (with $\mathrm{Na}_{2} \mathrm{O}+\mathrm{MgO}$ from 7 to $10 \mathrm{wt}$ \% , $\mathrm{K}_{2} \mathrm{O}<1$ wt.\%, and $\mathrm{CaO}$ from 13 to 16 wt. \%) [22]. Glasses are inherently susceptible to corrosion by their interaction with atmospheric moisture, and the complex construction of the magic lantern slides attracts dust and moisture, promoting that interaction [23-24]. Furthermore, special attention needs to be paid to the potassium-rich glasses. Although the amount of $\mathrm{CaO}$ is between 7 and $9 \mathrm{wt} . \%$, which may confer stability to the composition, there is a lack of other stabilizing agents in these glasses, and studies have shown crizzled glasses with $\mathrm{CaO}$ concentrations of as much as $10 \mathrm{wt}$. \% [22, 24-25].

Regarding the characterisation of the painting layers, changes in the colour palette over time were identified (Figure 2). Inorganic pigments were identified, as well as light-sensitive organic-based pigments. Shellac and mastic resins, possibly applied as varnishes were also identified. In all of the slides, known degradation products of paintings, such as metal carboxylates, were detected [12, 16-17].
These initial results on the material characterisation of both glass and painting materials, obtained within the Lanterna Magica project, have demonstrated the importance of an in-depth study on the materials and techniques used to produce hand-painted magic lantern slides in the eighteenth and nineteenth centuries, for a precise evaluation of their preservation state.

\section{Research Concept and Objectives}

The main goal of this research is to present a set of preventive conservation recommendations suited to collections of hand-painted glass slides. To propose these guidelines it was necessary to understand the characteristics and specific necessities of these collections and institutions that hold them.

The CP and MUHNAC collections were studied to determine which part of their collection represented magic lantern slides exclusively hand-painted or hand-painted over printed outlines, the slides' most common formats, movement mechanisms and types of constructions, composing materials, their state of preservation, and the most common degradation problems.

In addition, an online survey was sent to national and international institutions that hold magic lantern slides. The purpose was to have an overview of their characteristics, for instance in terms of number of slides per institution, their depiction techniques and dates, common damage observed, and the preventive and interventive conservation measures that have been undertaken. 

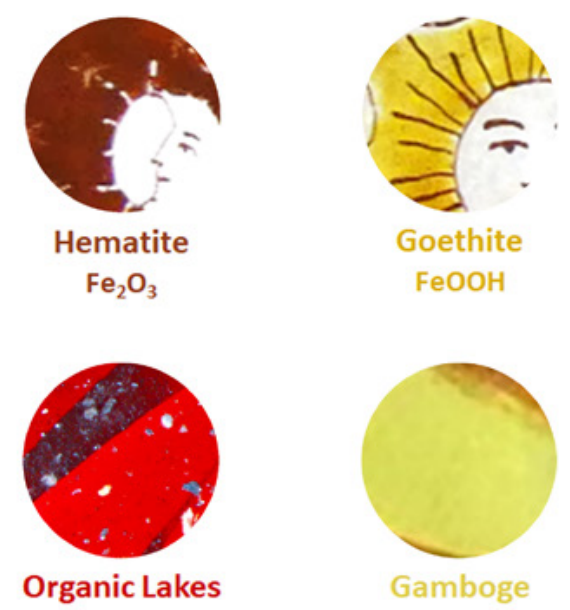

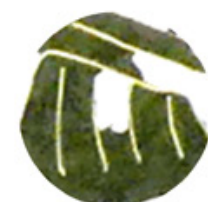

Copper Green

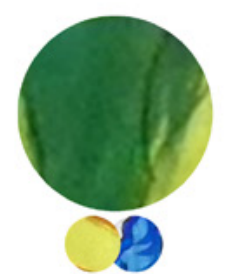

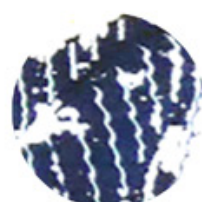

Prussian Blue $\mathrm{Fe}_{4}\left[\mathrm{Fe}(\mathrm{CN})_{6}\right]_{3}$

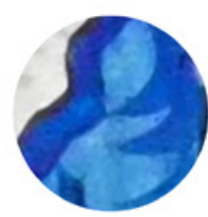

Prussian Blue

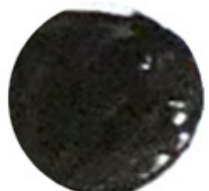

Carbon Black

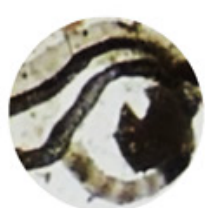

Carbon Black

Figure 2. Palette of the primary colourants identified in 18th and 19th century slides exclusively hand-painted from CP and MUHNAC collections. These colours were also mixed to produce other colours such as green, orange and purple. Details from 18th-century slides: hematite and goethite (inv. CP_ PCO02/011); and copper green, Prussian blue, and carbon black (inv. CP_PCo02/003). Details from 19th-century slides: organic lakes and carbon black (inv. ULISBOA-MUHNAC-UL000067), gamboge (inv. CP_PC3302/009), green (inv. CP_PC446), and Prussian Blue (inv. CP_CP3300/002) (photo credits CP: Ângela Santos; photo credits MUHNAC: Beatriz Rodrigues).

\section{Methodology}

\section{Study of CP and MUHNAC collections}

The CP collection comprises around 1300 magic lantern slides from the eighteenth to the twenty-first centuries attributed to France, Germany, Italy, Netherlands, Portugal, the United Kingdom, and the United States of America. The MUHNAC collection contains 49 slides produced in the nineteenth century, from England, France, and Germany. In these collections, only the magic lantern slides that were exclusively hand-painted, and those hand-painted over printed outlines were investigated.

From the ca. 1350 slides from both institutions, 333 slides of interest from the eighteenth and nineteenth century were identified (including the 20 slides previously studied). The following information, already documented by the institutions, was systematically assembled: inventory number, photography, producer, and local and date of production. Dimensions, classification according to their construction or movement mechanism and discursive genre, materials used, assessment of the state of preservation of each slide, and deterioration problems, were also catalogued within the scope of this work.

The classification according to their movement mechanism followed the classes defined by Barnes (1990) [26], and the discursive genre was identified by following the standards developed within the research project "A Million Pictures" (AMP) [10] and applied in online databases such as Linternauta [7].

The assessment of the apparent state of preservation was determined through careful macroscopic observation (i.e. by the naked eye) of the slides. A classification was attributed to each individual material that generally composes these slides (glass, painting, wood, paper and metal) as well as to the overall slide, considering the relative condition of its materials according to the broadly applied condition grading, as follows [22, 27]:

- good - stable, visibly undamaged;

- fair - acceptable and possibly stable, damaged, but without immediate action needed;

- poor - probably unstable and an interventive action is desired;

- unacceptable - severely weakened or actively deteriorating, and immediate interventive action is needed.

Twenty of these slides were analytically characterised in previous studies, as referred to in the section Research Context. For this reason, their state of preservation grade was attributed not only considering what was visible with the naked eye but also what was observed with the analytical techniques (e.g. Optical Microscopy (OM) and Fourier Transform Infrared Spectroscopy (FTIR).

The deterioration problems were documented according to the vocabulary widely used in condition reporting of cultural heritage, particularly in glass and paintings conservation (e.g. by Corning Museum of Glass and Canadian Conservation Institute) [28-30].

\section{Survey design}

An online survey entitled "Conservation of Magic Lantern Hand-Painted Glass Slides" was designed as a qualitative research tool, primarily to understand how collections of magic lantern glass slides are being preserved in different institutions. Since this work is part of an ongoing project, the survey is available through the Lanterna Magica project web site and the link https://goo.gl/forms/ofHmI7DZqMFNxokI2.

At the beginning of 2019, the survey was sent to 53 institutions known to the authors for their magic lantern 
slides collections, from 11 countries (Australia, Canada, France, Germany, Italy, Netherlands, New Zealand, Portugal, Spain, United Kingdom, and the United States of America). The institutions selected were mainly museums (43), but archives, universities and libraries were also included. In addition to these, an answer from a private collection was also gathered since institutions were also encouraged to share the link.

The first part of the questionnaire addresses the characterisation of the institution and its collection of magic lantern slides. In this part were included questions concerning the existence of someone responsible for this collection, their professional training, the total number of slides held, dates of production, and the slides' depiction techniques, specifically if the collection contained handpainted slides (either exclusively painted or hand coloured over printed outlines or photography).

Regarding the preventive conservation procedures undertaken, the institutions were asked if the slides were inventoried or catalogued, digitised, regularly monitored, and the environmental conditions in storage and display rooms. Within the section Environmental conditions, questions about relative humidity (RH), temperature, light, and the use of Integrated Pest Management (IPM) were posed. Conditions of storage and display were addressed, in terms of types of equipment and protective materials, as well as the slides positioning and organisation criteria.

The questionnaire also addresses the topics of previous interventive conservation procedures or restorations, the most common conservation problems that are observed in the slides, and whether the historical slides are currently being used in recreations of magic lantern shows and demonstrations. Finally, it includes a field that encourages the caretakers to add further observations and contact the authors.

\section{Development of Guidelines}

The preventive conservation guidelines were developed considering three main aspects: technical studies, questionnaire, and literature review. Technical studies on $\mathrm{CP}$ and MUHNAC collections allowed, for example, the identification of the slides' composing materials (from macro- to microscopic level), their state of preservation and main conservation problems, and types of constructions, which was essential to recommend suitable practices. The questionnaire intended to present an insight of the current preventive procedures undertaken into other institutions with the same type of collections to adapt the guidelines according to their necessities and difficulties, emphasising aspects that need more improvements. The literature review was mainly focused on magic lantern slides cataloguing and digital preservation, and on the susceptibility of each material identified, to propose the most appropriate conditions for these composite artefacts (e.g. the detection of light-sensitive materials in the paintings influenced the light recommendations). These guidelines were designed as a complement of the general preventive conservation standards currently established for cultural heritage collections [27, 30-37].

\section{Results and Discussion}

\section{A closer look at CP and MUHNAC collections}

Of the 333 slides of interest identified, 90 were exclusively hand-painted ( 82 from CP and eight from MUHNAC), and 243 were hand-painted over printed outlines (222 from CP and 21 from MUHNAC) (Figure 3). The great majority of these slides were produced during the nineteenth century, with only 11 being from the eighteenth century.

\section{Overview of CP and MUHNAC Slide Collections}

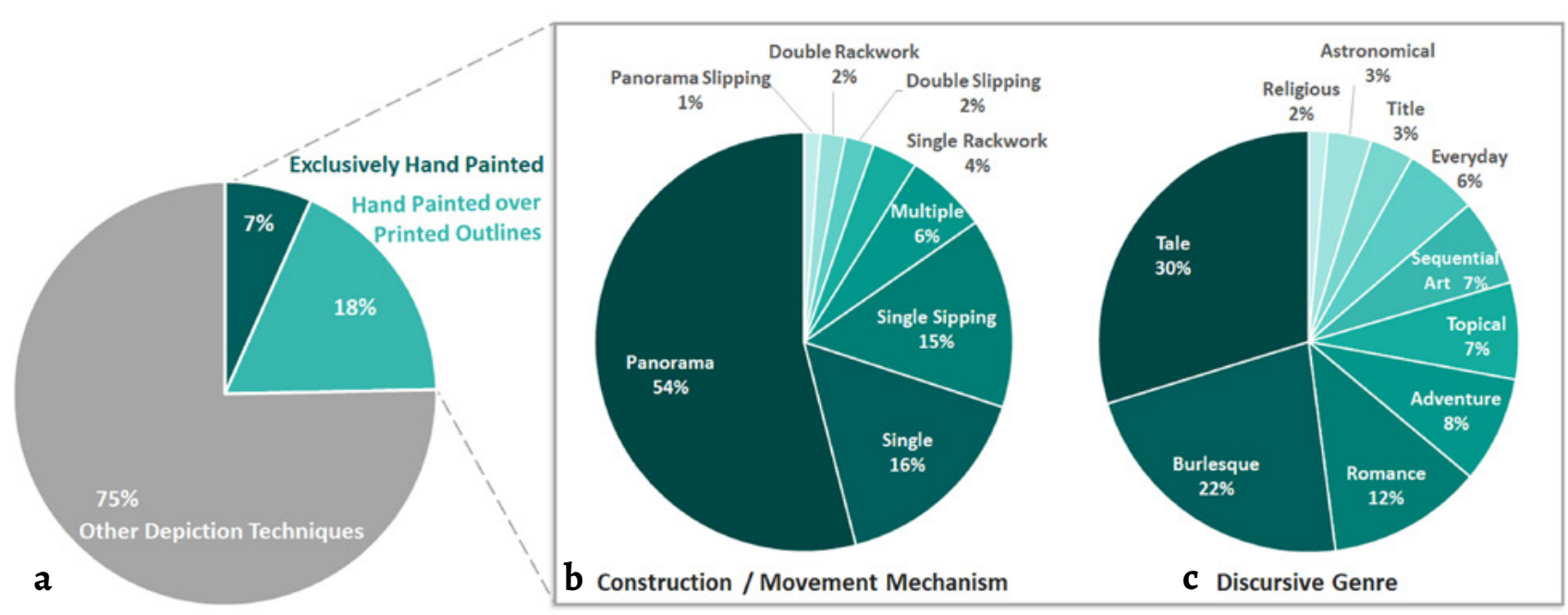

Figure 3. Overview of CP and MUHNAC collections of magic lantern glass slides: $a$ ) percentage of slides exclusively hand-painted, and hand-painted over printed outlines in both collections; b) distribution by type of construction or movement mechanism, following the classification from [26]; c) distribution by discursive genre, following the categories developed in Linternauta [7]. 

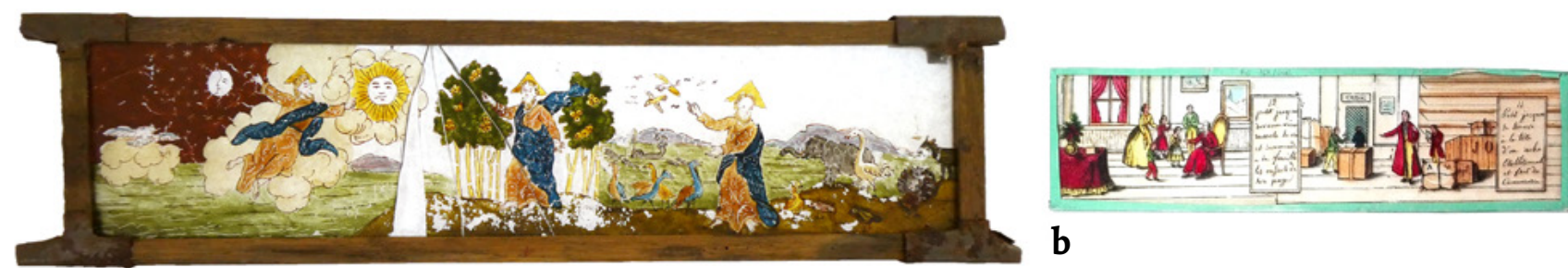
b

a

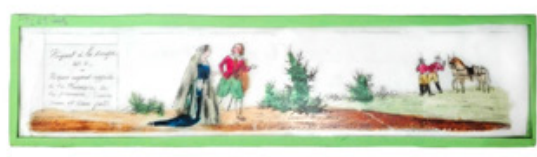

c

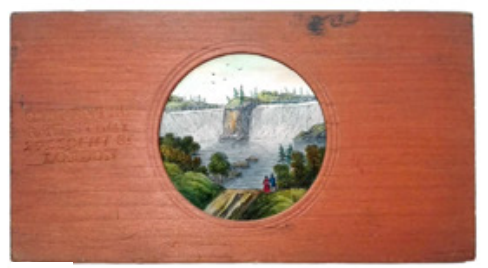

e
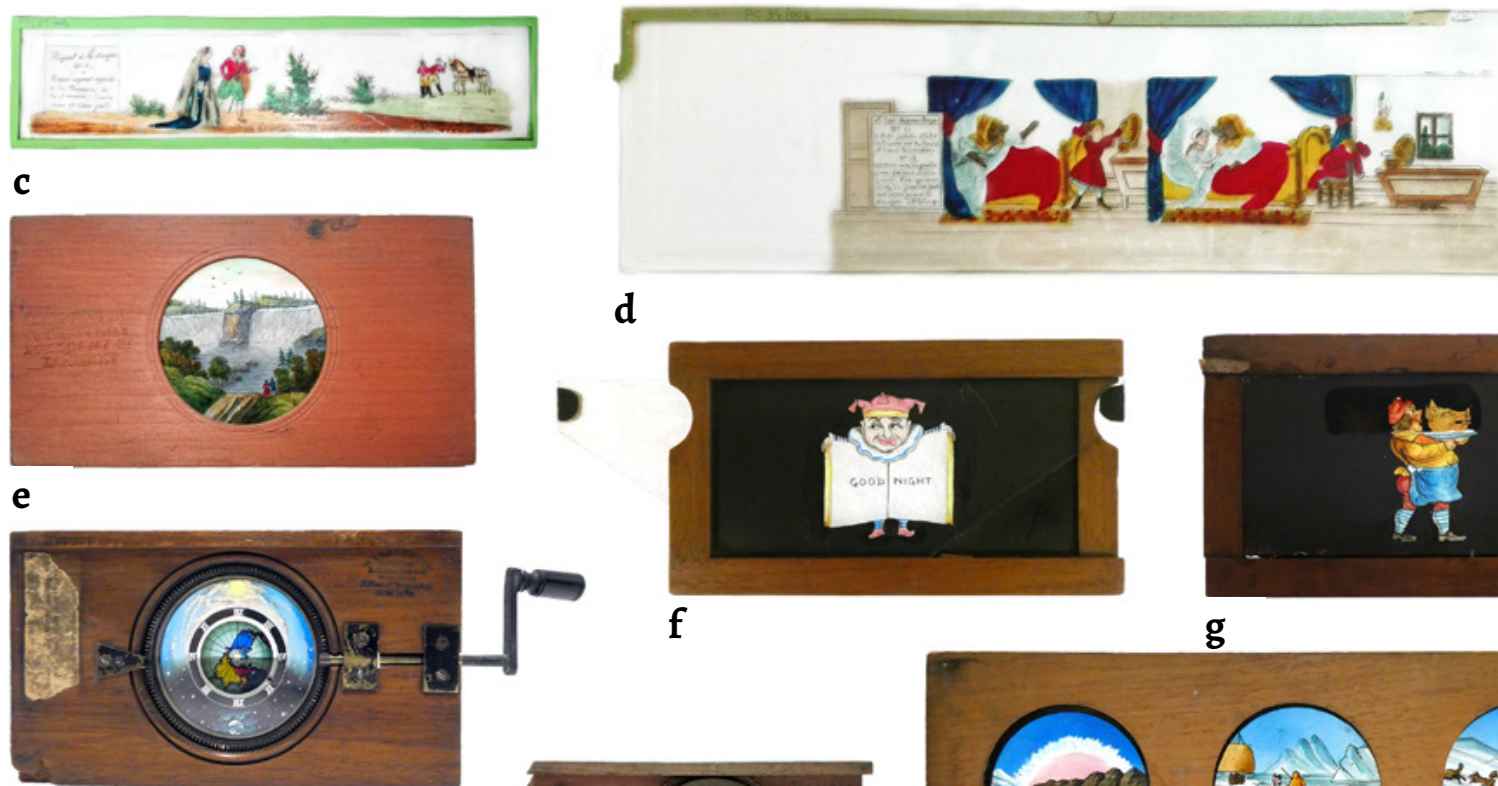

d

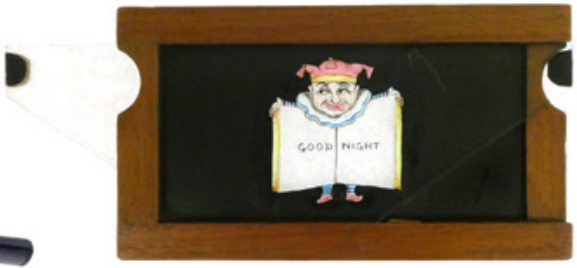

f
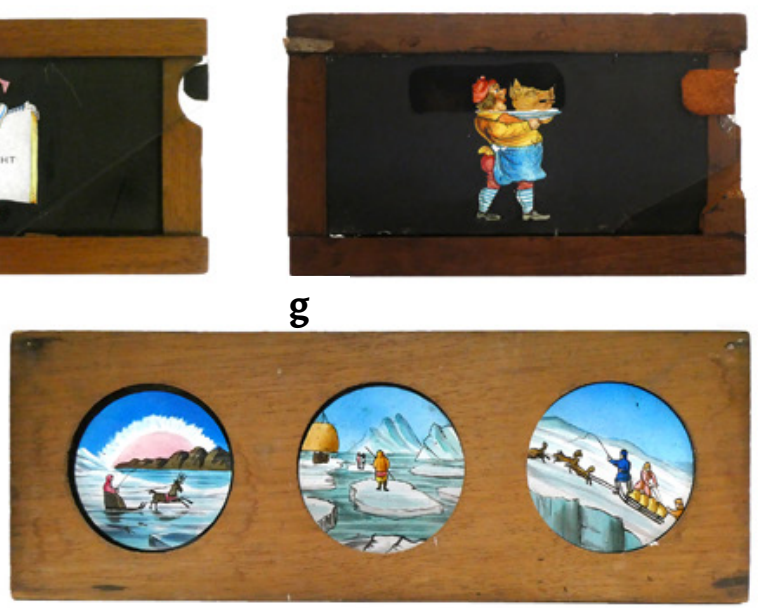

g
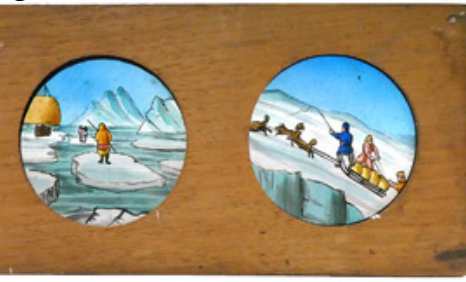

$5 \mathrm{~cm}$

i

j

Figure 4. Examples of the most common discursive genres and constructions or movement mechanisms of the slides investigated from CP and MUHNAC collections: a) religious, panorama slide (inv. CP_PCoo2/o11); b) adventure, panorama slide (inv. CP_PC168/006); c) romance, panorama slide (inv. CP_ PCo23/005); d) tale, panorama slide (inv. CP_PC034/003); e) topical, single slide (inv. CP_PC189/0012); f) title, double slipping slide (inv. CP_PC3300/004); g) burlesque, single slipping slide (inv. ULISBOA-MUHNAC-UL000068); $h$ ) astronomical, single rackwork slide (inv. CP_PC3301/002); $i$ ) title, double rackwork slide - chromatrope (inv. CP_PC436/003); j) adventure, multiple slide (inv. CP_PC445/003) (photo credits: Ângela Santos).

Details of the classifications attributed to the slides investigated may also be observed in Figure 3. The most common types of construction or movement mechanisms identified are the panorama slide, single slide, single slipping slide, and multiple slide. Regarding their discursive genres, the great majority are ludic. The most common genres are tale, burlesque, romance, and adventure. Examples of slides with different types of construction and discursive genres from both institutions are presented in Figure 4.

\section{Assessment of the state of preservation}

Of the 333 slides investigated, only 300 slides were available for assessment of the apparent state of preservation (78 slides exclusively hand-painted, and 222 slides hand-painted over printed outlines) since the other 33 slides were on display and their careful examination was not possible.

The results of the evaluation of these 300 slides, summarised in Figure 5, revealed that almost $80 \%$ of the slides appear to be in good or fair condition; nevertheless, more than $10 \%$ are severely weakened and in urgent need of interventive conservation treatments. The slides exclusively hand-painted presented a higher percentage of slides in an unacceptable condition when compared to slides that were hand-painted over printed outlines. However, this does not necessarily mean that one technique is more susceptible to degrade than the other. It is worth to mention that 11 of these 15 exclusively hand-painted slides in unacceptable condition were produced during the eighteenth century and the remaining are from the nineteenth century. Factors such as the date of production, the materials that were used to produce them, the number of times they were projected, the conditions in which the slides were kept over the years, have an influence in the condition in which they are today. From the five types of materials that were individually assessed in these 300 slides, the painting was by far the most affected.

The 20 slides analytically characterised in previous studies, were evaluated with more precision by complementing the macroscopic observation with the analytical results. The 11 eighteenth-century slides considered in an unacceptable condition, have damages visible with the naked eye including 
Apparent State of Preservation

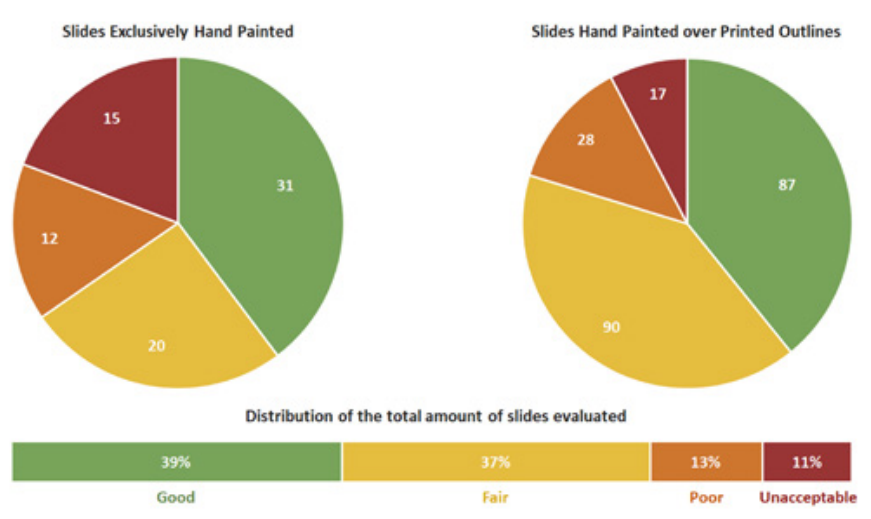

Figure 5. Overview of the apparent state of preservation of 300 slides, exclusively hand-painted and hand-painted over printed outlines, from the CP and MUHNAC collections.

paint cracks and loss, powdering and loss of the paint adhesion to the glass support. Using different analytical techniques in the painted surface, metal carboxylates and oxalates (known degradation products in paintings) were detected, along with colour alteration, and extensive microcracking in the paint layer. On the areas where the paint had been lost, a layer with craquelure, of what appears to be a residue of the paint binder, can be observed. No microcracking was found on the unpainted glass surface. Further investigation on the glass support will be necessary to determine if, in addition to the failure of the paint binders, the microcracking in the paint and the loss of adhesion to the glass support may have been enhanced by the possible deterioration of the glass.

Seven of the nine nineteenth-century slides were considered in good and fair conditions, with only a few small and localised lacunas in the paint, and the other two were in poor condition, with visible signs of paint deterioration that included cracks and flaking. Although only these two last-mentioned slides have visible signs of physical and chemical deterioration, the material characterisation showed evidence of deterioration at the molecular level in all of the slides. Therefore, appropriate preventive conservation procedures are necessary to reduce the evolution of the degradation processes.

\section{Common degradation problems}

Examples of the most common degradation problems in the slides investigated can be found in Figure 6. As expected, given the intensive handling and exposure to aggressive conditions of light and temperature during projections, the magic lantern slides present an assortment of damage that may be related to these factors, as well as inadequate conditions of storage and display.

Damage such as fractures and lacunas in the glass support, wear and tear of the paper used as a frame or handle, and scratches on the wood frames and paint layers, are possibly the result of excessive or careless handling. The abrasion of the painted surface in preferential direction is frequently found, most probably due to the horizontal movement of the slides during projections.

As the results of the preservation assessment point out, the most sensitive materials are the paint layer due to their inherent properties. Crack patterns, flaking and lacunas are often observed in the paint layer, which is possibly due to the deterioration of the binders caused by its excessive exposure to light and high temperatures.

The outlines printed onto the glass are frequently heterogeneous and have small lacunae. In some slides, losses of colouring material are only visible in areas adjacent to the outline lacuna. If a black glass enamel was applied in these slides, the outline detachment might be related to the enamel deterioration, incompatibility between the glass support and the enamel, or insufficient contact surface due to the small amount of enamel applied. Further investigation will be fundamental to determine the nature of the outlines that present conservation problems, determine which printing techniques and materials are more prone to loss and the reasons behind its deterioration.

The slides' exposure to poor environmental conditions and lack of preventive maintenance is the cause of the most common degradation problem: the presence of dust and grime over the surface of the slides. Distortion, mould or fungi stains and insect damage are frequently found in wooden frames, as well as corrosion of the metallic parts and evidence of white spots on the glass support. These white spots are observed between glasses overlaid without ventilation and may be crystalline salts resulting from glass deterioration or fungi growth. Further analysis will be necessary to discern what caused this damage.

\section{Survey of national and international institutions}

Twenty answers from eight countries were obtained, essentially between February and April 2019. Fifteen of the answers were from museums (one from Canada, one from France, one from Germany, two from Italy, five from the Netherlands, two from Portugal, and three from the United Kingdom), two from archives (Australia and United Kingdom), two from universities (United Kingdom), and one from a private collection.

Although the number of respondents is far from being representative of the number of institutions that hold magic lantern glass slides, the authors present the results obtained as a brief insight into the reality of these collections.

Of the 20 entities that answered the survey, 19 have someone responsible for the collection of magic lantern glass slides; however, only nine institutions have someone with professional training in the conservation field.

The number of magic lantern slides in each collection varies significantly from 50 to 50000 and make a total of nearly 150000 slides surveyed. Two of these collections have slides produced in the seventeenth century, 11 hold slides from the eighteenth century, all of the 20 collections 


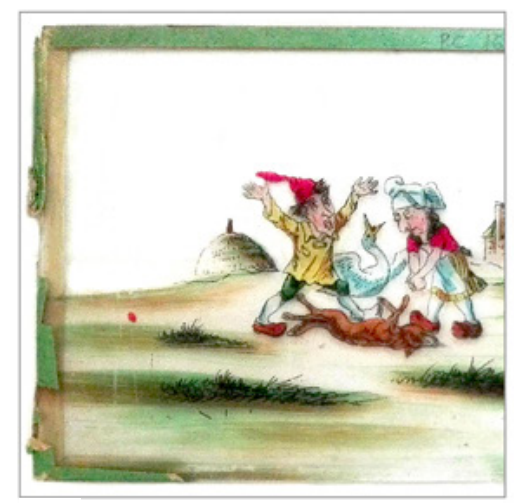

$\mathbf{a}$

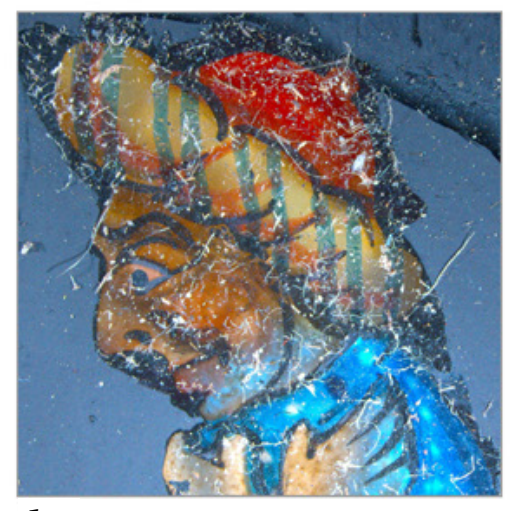

\section{d}

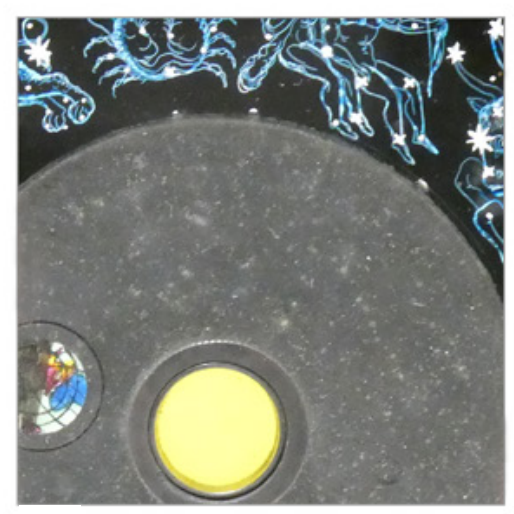

g

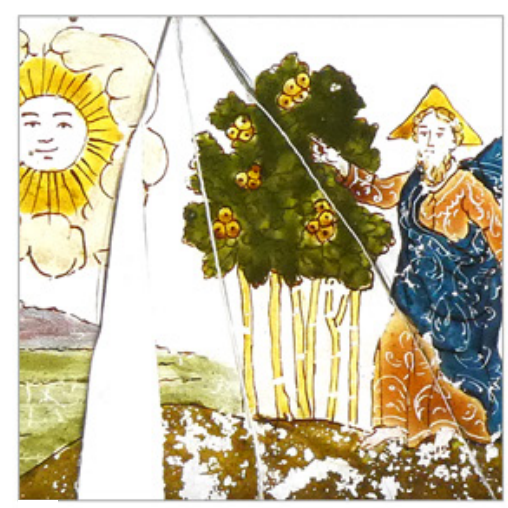

b

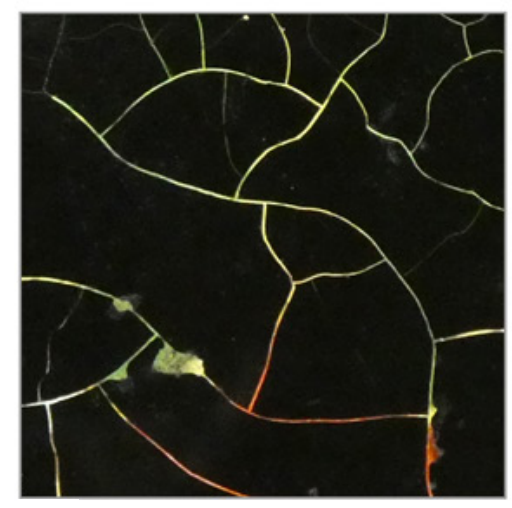

e

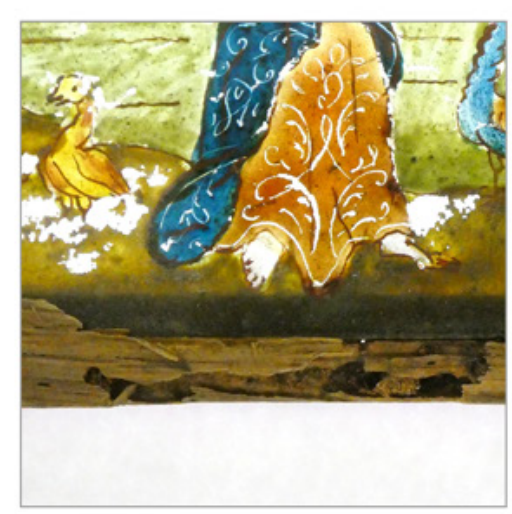

h

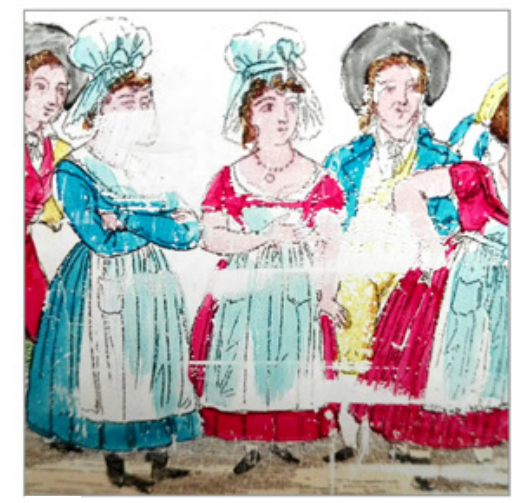

C

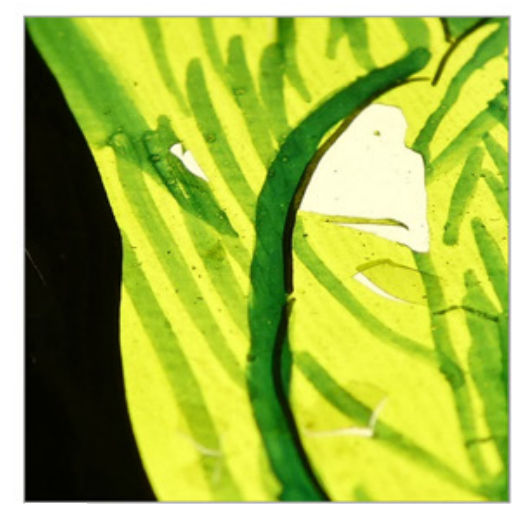

f

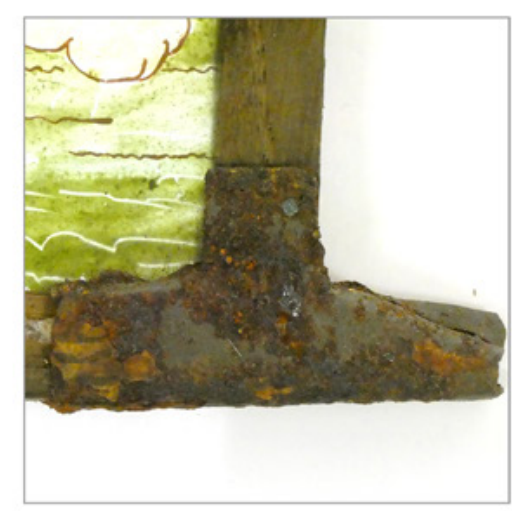

i

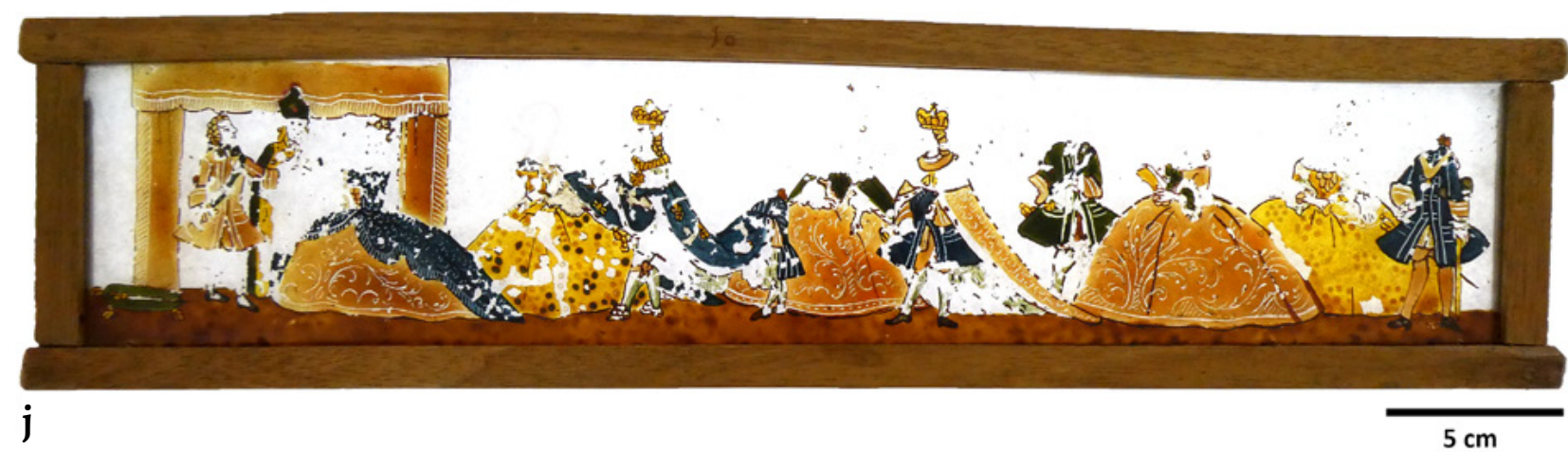

Figure 6. Examples of common degradation problems observed in the slides investigated from CP and MUHNAC collections: a) paper wear and tear (inv. CP_PC165/005); b) glass fracture and lacuna (inv. CP_PC002/011); c) abrasion of the painted surface in preferential direction (inv. CP_PC166/006); d) dust on the surface (inv. ULISBOA-MUHNAC-UL000067); $e$ ) cracks pattern on the painting (inv. CP_PC3302/006); f) loss of adhesion and detachment of the paint layer (inv. CP_PC446); g) white spots of deterioration on the enclosed glass surface (inv. CP_PC3301/005); $h$ ) wood with insect damage (inv. CP_PCo02/011); i) metal corrosion (inv. CP_PCo02/011); ) wood distortion (inv. CP_PCO02/008) (photo credits CP: Ângela Santos; photo credits MUHNAC: Beatriz Rodrigues). 
contain slides from the nineteenth century, and 18 of them also hold slides from the twentieth century. In terms of depiction techniques, 16 of them have slides exclusively hand-painted, and slides hand-painted over printing or photographic techniques.

\section{Preventive conservation procedures}

Concerning the preventive conservation procedures undertaken, 19 of these collections have their slides inventoried, and 18 have their slides digitised and the digital images kept in databases. These are essential steps to ensure their clear identification, preservation of their imagery, and one of the best means to reduce their handling and make them readily available to be studied.

Regular monitoring is of most importance to preventively guarantee the continued safety of cultural collections. It should concern factors such as temperature, relative humidity, light, pests, pollutants, equipment, facilities, among others, but it also should include the regular and individual monitoring of the objects itself to detect alterations that may be occurring. Regardless its significance, only 10 of these collections are regularly monitored, which may be related to management of time and personnel that this task requires.

The control of environmental conditions in storage and exhibition rooms is an essential conservation measure. All 20 collections confirmed holding slides in storage, but only 13 manage to control the environmental conditions in these rooms. Eleven institutions also have slides in exhibition rooms of which nine can control the environment in these rooms. Furthermore, 12 of the surveyed institutions have implemented an Integrated Pest Management (IPM) program.

$\mathrm{RH}$, temperature, and light conditions were similar in storage and display rooms, within the same institution. Of the 20 collections, 12 registered $R H$ values between $40-60 \%$, while two registered it between $20-40 \%$ (six did not answer). In terms of temperature, 18 reported temperatures between $10-25{ }^{\circ} \mathrm{C}$, of which almost $80 \%$ were between $15-20{ }^{\circ} \mathrm{C}$ (two did not answer). According to these results, these institutions appear to conserve their collections in favourable conditions considering that the lower percentages of $\mathrm{RH}$ and temperature were indicated by institutions that hold photographic slides.

Light intensity in the 11 institutions' exhibition rooms ranges from $<50$ to 150 lux, but in the 20 storage rooms, the light can reach 200 lux, which is extremely high considering the 50 lux recommended for these collections In storage, 13 of the 20 institutions referred to the use of fluorescent lights, followed by Light Emitting Diode (LED) (five), and incandescent lights (two). In the 11 exhibition rooms, the most common light source used is LED (by six institutions), followed by fluorescent and incandescent (three did not answer). In 14 of the 20 storage rooms and eight of the 11 exhibition rooms, the ultraviolet (UV) radiation is avoided by using non-emitting or filtered lights along with the absence of windows or by blocking existing windows. These results appear to demonstrate that the light sources are chosen more carefully in display rooms than in storages; however, this might not be a problem if the collections are kept inside containers that protect them from light.

The furniture or equipment used to store or display magic lantern glass slides are frequently made of wood, metal, and glass. In storage areas, metal cabinets are more common, followed by wood cases and wood cabinets with glass windows, while in exhibition rooms, glass cases are the most common, followed by wood and glass cabinets. Only six of the 11 institutions can control the environment inside the exhibition furniture, keeping the conditions similar to the rooms.

Of the 20 institutions, 16 confirmed that the magic lantern glass slides are not in direct contact with the storage or exhibition furniture, using mostly acid-free paper or card as a separator. Boxes and envelopes are frequently used to store glass slides and are commonly made of acid-free or neutral $\mathrm{pH}$ card or paper. However, four of these institutions also uses the original wood boxes to store them. These results have shown that one of the main concerns in these collections is the common use of wood furniture and boxes to keep the slides, given the amount of harmful volatile compounds that this material may release to the environment, especially if it lacks air circulation inside the container.

Regarding the position in which the slides are kept, 14 of these collections are stored vertically. This may be dangerous if the pictorial layer is weakened. In terms of organisation criteria, the most common was by size format and discursive genre, followed by depiction technique, and producer or country of production.

The re-enactment of shows is a common practice among magic lantern enthusiasts, private collectors, and institutions such as archives and museums. Eleven of the surveyed institutions have magic lantern shows, of which seven use original slides from their collections instead of replicas. The work developed to rediscover and re-enact these engaging performances has brought to life the original intention of these historical objects. However, the submission of historical slides to heavy handling, intense light and temperature during projections puts them at risk, therefore more strategies to produce replicas of original slides should be pursued.

\section{Interventive conservation procedures and final observations}

Half of the 20 collections have slides that have undergone interventive conservation procedures and restorations. These interventions included overall cleaning (unpainted areas), consolidation of cracks and bonding of glass, removal of metal oxidations, application of protective coatings on the metallic parts, and replacement of screws in slides with complex movement mechanisms. The most common deterioration problems observed were the same as those 
identified in CP and MUHNAC collections, mentioned in the section Common degradation problems.

Additional comments from the caretakers were considered extremely relevant for this study. A large number of slides and the lack of time and personnel dedicated to these collections were pointed out as the main drivers for non-application of conservation measures such as inventorying, digitisation, assessment of conservation state, and regular monitoring. The caretakers also shared their difficulty in finding information about these types of collections, especially regarding preventive and interventive conservation. It is also worth mentioning the case of one institution, holding 20000 slides, that was not able to answer to the survey due to the lack of information on the collection and conservation measures undertaken.

\section{Preventive conservation guidelines for hand-painted slides}

Heritage professionals recognise preventive conservation as the most effective mean of promoting the long-term preservation of cultural property, and the primary goal of this work was the development of guidelines for the preventive conservation of magic lantern slides. The guidelines here presented are the first proposal and will be further developed in the future. These recommendations address: inventory standards; appropriate environmental conditions; storage and exhibition materials; handling; and performative re-enactment shows. A summary of the guidelines can be consulted in Table 1 and further details are provided below.
It should be noted that photographic slides and slides made by chromolithographic processes on glass or acetate substrates were not addressed since they are outside the scope of this work. Although certain preventive conservation measures are transferrable to all types of slides, specific environmental conditions proposed here may not be the most appropriate for these objects.

\section{Recommendations for the collection assessment, inventory, and digital preservation}

The establishment of a detailed inventory of the collection with the attribution of a unique identifying number to each object (physically linked to it), is essential since it allows a clear identification of each object reducing the risk of dissociation. General information about the object, background, and associated documentation should be stored in a digital database linked with the inventory number of each object. This inventory database should include entries for each slide that: 1) mention if it belongs to a series; 2 ) contain information on the materials it is composed of (e.g. glass, wood, paper); 3) include manufacturing and depiction techniques; 4) contain a description with dimensions and type of construction or movement mechanism according to the classification defined by Barnes (1990) [26]; contain a classification in terms of discursive gender according to current metadata standards (e.g. the ones defined by the research project "A Million Pictures" (AMP) and applied in online databases such as Linternauta and LUCERNA the Magic Lantern Web resource $[7,38])$. An evaluation of the conservation state, as comprehensive as possible, of the

Table 1. Summary of the preventive guidelines recommended considering the different materials that may compose a hand-painted magic lantern glass slide.

\begin{tabular}{|c|c|c|}
\hline Causes of damage & Recommendations & Additional notes \\
\hline Temperature & $\sim 20^{\circ} \mathrm{C} \pm 5^{\circ} \mathrm{C}$ & - Avoid fluctuations $>5^{\circ} \mathrm{C}$ \\
\hline 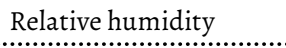 & $\sim 45 \% \pm 5 \% \mathrm{RH}$ & - Avoid fluctuations $>5 \% \mathrm{RH}$ \\
\hline Light & $\begin{array}{l}\sim 50 \text { lux } \\
\text { - LED lamps }\end{array}$ & $\begin{array}{l}\text { - Reduce as much as possible: } \\
\text { - UV and IR radiation } \\
\text { - Light levels } \\
\text { - Exposure time }\end{array}$ \\
\hline Fine particles and pests & $\begin{array}{l}\text { - Keep the collections and spaces clean } \\
\text { - Install air pollution filters } \\
\text { - Implement IPM }\end{array}$ & - Regular monitoring \\
\hline Storage and display & $\begin{array}{l}\text { - Use metal, glass, polyethene, polypropylene, cotton, } \\
\text { linen, and other neutral pH materials } \\
\text { - Avoid the materials' contact with the painted surfaces } \\
\text { of the slides } \\
\text { - Allow ventilation between the slides and the storage/ } \\
\text { display materials, and each other } \\
\text { - Allow ventilation inside the storage or display } \\
\text { equipment }\end{array}$ & $\begin{array}{l}\text { - Use a layered storage system } \\
\text { - Give preference to the horizontal disposition of the } \\
\text { slides with the painting layer facing up }\end{array}$ \\
\hline Handling & $\begin{array}{l}\text { - Avoid handling as much as possible } \\
\text { - Avoid any impact and vibrations }\end{array}$ & - Handle with very clean hands or use nitrile gloves \\
\hline Projection shows & - Use replicas & $\begin{array}{l}\text { - Intense temperature and light can damage the } \\
\text { original slides }\end{array}$ \\
\hline
\end{tabular}


slides including a rating based on the condition grading scale described in the section Methodology [27], and high-quality digitisation (e.g. by scanning or photographing) should also be present. Guidelines for the most appropriate ways to digitise magic lantern glass slides were also developed during the AMP project and published by Sabine Lenk et al. [39]. An excellent way to digitally preserve the slides, reduce the need of handling the original artefacts, and make them easily accessed is by adding their digital images and all the information available to internal or online databases such as the ones previously mentioned.

\section{Environmental conditions}

Controlling the environmental conditions in which works of art are stored, exhibited, and transported is one of the most effective preventive conservation strategies to preserve them and extend their lifetime.

The most significant environmental factors that contribute to the deterioration of magic lantern glass slides include temperature, relative humidity, light, dust accumulation, and insect and fungi activity. To avoid, detect, report, and treat potential damage and threats as soon as possible, it is imperative to implement regular monitoring of the collections.

Hand-painted magic lantern glass slides are composite objects that frequently contain materials such as glass, paints and varnishes, wood, paper, and metal. Each one of these materials react differently to environmental conditions, have distinct needs, and may contribute to the deterioration problems of other materials that are present. For example, the contraction of the painting materials due to low RH may result in their cracking or detachment from the glass support since the glass does not behaves the same way. Additionally, the materials can have undesired interactions with each other, for instance glass deterioration can be promoted by the presence of hydrophobic materials like wood and paper, and copper-green organic pigments are more prone to deteriorate in the presence of natural resins [40].

Due to the combination of such diverse materials, it is necessary to find a balance in terms of the most appropriate conditions of temperature, relative humidity, and light. The proposed conditions take into consideration the lower and higher values currently recommended for each one of the materials composing hand-painted magic lantern slides.

\section{Temperature and relative humidity}

Hand-painted glass slides should be stored and displayed in areas in which the temperature and relative humidity (\% RH) are kept stable at $20^{\circ} \mathrm{C} \pm 5$ and $45 \% \pm 5 \mathrm{RH}$. However, more important than reaching the suggested values for temperature and $\mathrm{RH}$, it is crucial to avoid fluctuations of more than $5{ }^{\circ} \mathrm{C}$ and $5 \% \mathrm{RH}$ in 24 hours $[33,34]$. Both environmental factors are directly related, considering that when the temperature increases the $\mathrm{RH}$ lowers and viceversa. Fluctuations in either can induce stress on the object and lead the rapid expansion and contraction of certain materials, causing damage observed in the collections, such as cracks, flaking, and loss of adhesion of the paint layers, and the distortion, delamination or fractures in the paper and wood [35-36].

Higher temperatures can accelerate chemical deterioration of the painting materials, increase the flexibility of natural resins, and can turn them stickier. These temperatures will enable the paints to hold dust more easily, increase pest activity, and cause dehydration due to the resultant decreasing of $\mathrm{RH}$, especially dangerous to the wood and paper. Higher RH can promote mould and fungi growth that damages the wood, paper, glass support and paint layers, and the corrosion of glass and metal. As observed in the collections, high RH is particularly dangerous in slides where two glasses are overlaid without ventilation, creating condensation between them, since it increases the reaction of glass with atmospheric water (which can lead to leaching, dissolution and deposition of alkali salts on the glass surface, consequently causing the detachment of the paint layer) and fungi growth, enhancing its deterioration (Figure 6g) [23-24, 41-42]. Too low temperature or $\mathrm{RH}$ can cause painting materials, wood, and paper to shrink and fracture and increase microcracking in already deteriorated glass $[23,32,36]$.

\section{Light}

Magic lantern glass slides should be stored in the dark. The recommended light level for displaying is around 50 lux, the light source, ideally artificial, should not produce any heat nor emit ultraviolet (UV) or infrared (IR) radiation (e.g. Light Emitting Diode (LED) lamps) and the exposure time should be kept to a minimum [32, 36]. These recommendations are based on the presence of light-sensitive materials such as wood, paper, organic binding media (e.g. varnishes) and organic-based colourants [36].

The exposure to natural and artificial light can damage the light-sensitive materials present in hand-painted magic lantern slides, causing, for example, colour alteration and embrittlement of organic materials. Any heat produced can accelerate chemical deterioration processes and cause disintegration of these materials, particularly the thin paint layers.

Natural UV radiation can be removed by blocking natural light or installing UV filtering material over windows. To eradicate the UV and IR emission inside the storage and exhibition areas, artificial light sources that do not emit this type of radiation or filtered coated lamps should be used. However, if the transition to this lightning is not immediately possible, the light sources should be kept away from the objects, and air circulation systems should be used to help control heat build-up [27, 29, 36, 43].

Exposure time should be controlled by implementing object rotation plans to reduce cumulative light damage, by defining which objects will be displayed and for how long. 
These object rotation plans should be developed considering that each slide should not be exhibited for longer than six months over five years at a maximum of 50 lux (i.e. 90,000 lux hours when exhibited for 10 hours a day) [36]. If the maximum of 50 lux is exceeded, the exposure time must be proportionally reduced (e.g. at 100 lux it can be exhibited for a maximum of three months over five years). The installation of motion detectors that only activate the light when visitors are close to the slides can also be an excellent strategy to reduce the light exposure time.

\section{Fine particles and pest control}

Particulate matter, such as dust and grime, is particularly damaging for magic lantern glass slides. The accumulation of these fine particles changes the visual appearance of the objects (Figure $6 d$ ), and blocks the passage of light, when projected, interfering with its original purpose, and is abrasive. Abrasion is particularly dangerous in slides with movement mechanisms that can scratch the painting every time the slide is manipulated. Depending on the particle composition, dust can be the main driver to a slides' deterioration, since it can be highly hygroscopic, become adhered to the materials, promote mould and fungi development, and can provide nutrients for insects that can severely damage the wood and paper materials (Figure $6 h$ ). High RH (>65\%) can also promote the growth of mould, fungi and insects, and must be avoided [32, 36, 44].

The presence of fine particles should be controlled to reduce its harmful effects, for example by installing pollution filters in the ventilation and air conditioning systems, and by using high-efficiency particulate air (HEPA) vacuums cleaners. The collections and areas in which they are stored and displayed should be kept clean, and with regular maintenance and monitoring of Integrated Pest Management (IPM) [36].

\section{Storage and display}

Magic lantern slide collections should be organised primarily according to their depiction technique and materials due to their different conservation needs.

Magic lantern slides must be stored and displayed with chemically stable and neutral materials to avoid the release of harmful substances that can accelerate the deterioration processes. Metal (e.g. steel), glass, polyethene, polypropylene, cotton, and linen are considered safe materials to use in museum collections. However, their compositions must be verified since there are manufacturing processes with coatings and additives that can be harmful. Nevertheless, the slides should never be in direct contact with storage or exhibition furniture nor with other slides. A thin foil of polyethene foam can be used to separate the slides from the furniture and, pieces of thicker polyethene soft foam may be placed on some of the edges to allow ventilation not only between the slides and the furniture, but also between slides. Besides controlling the temperature, $\mathrm{RH}$, light levels and pollutants in the storage and display rooms, these factors should also be controlled inside the storage and display cases. These cases must always allow ventilation to avoid the creation of condensation in the interior and increase, for example, glass deterioration, as discussed in the section Temperature and relative humidity.

Metal drawers or open shelves can be a good storage option to organise and protect the slides from environmental and physical risks [37]. For the first, soft-sliding drawers should be chosen to avoid vibrations that may damage weakened slides, when opening or closing the drawers. In an open shelf, a set of slides can be stored inside custom-made boxes adjusted to their dimensions, using, for instance, rigid polypropylene sheets or card with neutral $\mathrm{pH}$ for the external structure and polyethene foam to build the interior. The box should have exterior holes and allow for the slides to be separated from the box and from each other to enable ventilation (Figure 7). Organise the magic lantern slides according to their dimensions or type of construction is especially recommended when storing in boxes. This criterion not only allows the optimisation of storage space, but it also a

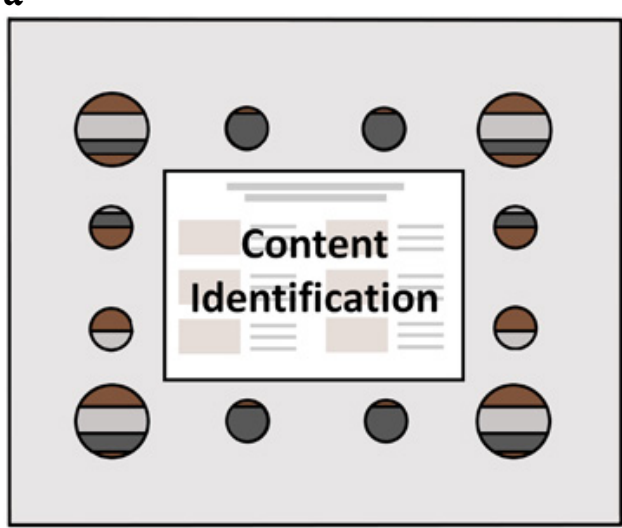

b

Interior

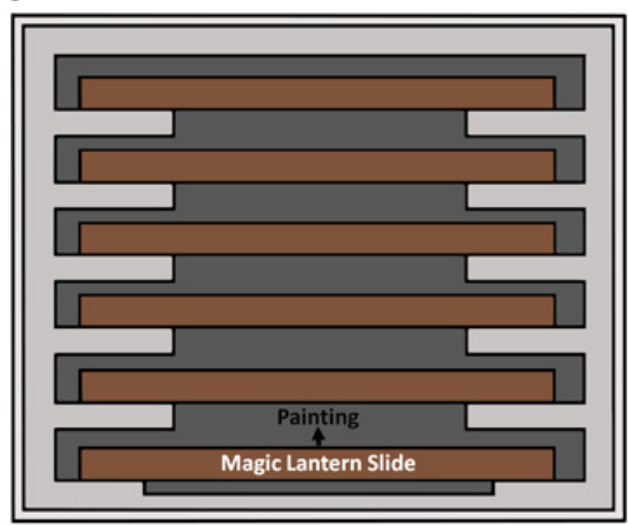

Figure 7. Example of a costume-made box to store magic lantern slides: a) front view of the box exterior, with holes to allow ventilation and brief information about its content to reduce handling; $b$ ) front view of the box interior, where the slides are in horizontal position with the painting facing up and are separated from each other and from the protective materials to allow ventilation. 


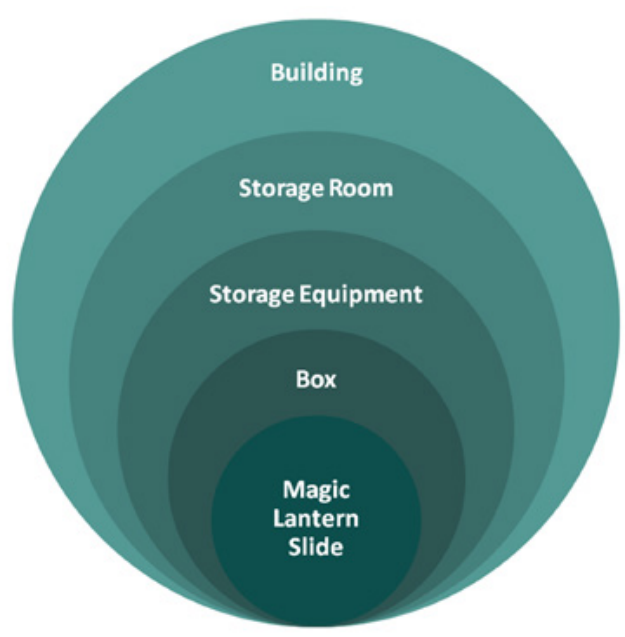

Figure 8. Scheme of a protective layered storage system for hand-painted magic lantern slide collections, adapted from [31].

organises the slides according to their purpose of use (e.g. slides with $11 \times 3 \mathrm{~cm}$ were used in "toy lanterns" and slides with $21 \times 6 \mathrm{~cm}$ would have been used in big performances) which may be useful for their study. However, it is imperative to find solutions so that none of the protective materials touches any painted surface to avoid physical damage, and the drawers or boxes have small openings to allow ventilation. A layered storage system where each layer adds protection to the slides is presented in Figure 8.

Metal cabinets with see-through glass doors can be useful for exhibiting the slides. Depending on the conservation state of the slides, they can be stored and displayed in horizontal, angled or vertical position. The horizontal distribution with the painting facing up is always preferred, particularly if the painting layer is weakened. The vertical position may cause fragments of severely weakened paint to detach from the glass and fall, as it was observed in the collections studied.

Wooden cases or other equipment should be avoided since wood (e.g. oak and composite wood boards such as Medium Density Fibreboard (MDF), often found in more recent cases) emits Volatile Organic Compounds (VOC) [35]. Pollutants emitted by the wood such as formic acid, acetic acid, and formaldehyde, are particularly damaging to the slides' glass support. These compounds can react with soda silicate glasses, leading to the formation of crystalline sodium formate at the surface, causing chemical and structural damage in the glass [45].

\section{Handling}

All magic lantern glass slides can be physically damaged by incorrect handling: the glass support can break with pressure or impact; the wood frame is susceptible to scratches and dents; the paper frequently used as a frame or handle on slipping slides (e.g. Figures $4 f$ and $4 g$ ) can suffer from wear and tear; and when exposed to or in contact with a moving glass, the painting can easily suffer from abrasion, and if deteriorated, a slight impact can cause the detachment and loss of paint. Therefore, handling should be avoided as much as possible.

When necessary, the glass slides should be carefully handled (touching only unpainted areas) and, to avoid the deposit of sweat and oil from the skin, the hand must be clean and dry at all times, or nitrile gloves may be worn. Although cotton gloves are frequently used in museums and archives, they are not recommended since they can be too slippery to handle glass, and cotton threads may get stuck on rough surfaces, for instance, if the slides have a weakened paper or wood frame [35].

Each set of drawers or boxes in storage should present, on the most visible face, summarised information about the slides it contains (e.g. inventory number, and photograph of each slide) to reduce the need of handling (Figure 7).

\section{Strategies for demonstrations and recreation of magic lantern shows}

Currently, it is a common practice to provide public projection shows with magic lantern slides to demonstrate how magic lanterns were operated and the original purpose of the slides, rekindling the magic lantern experience.

However, original slides should not be used in these situations, as their submission to intense light, temperature and handling during projections can be damaging. The use of replicas is recommended for this purpose. One of the goals of the project Lanterna Magica is to develop strategies to easily produce high-quality replicas of original slides for projections.

It is noteworthy to mention that new LED illumination systems for installation on standard magic lantern projectors are available on the market (e.g. Celsun). These LED Lime-Light systems are a better option to reduce the production of heat, UV, and IR radiation when compared to the original light sources (e.g. lime-light or incandescent bulbs). However, the light focused on the slides ( 9000 lux) is far more intense than original slides can be safely exposed to (50 lux), so the use of replicas continues to be the preferred recommendation.

If the production of painted replicas cannot be afforded, other solutions of inferior quality may be explored, for instance by photographing the original slides, printing them on acetate sheets with the same dimensions, and enclosing them in card frames, as used by the Portuguese Cinematheque (Lisbon).

\section{Final remarks}

The study of magic lantern collections of two Portuguese institutions (CP and MUHNAC) as well as the overview of 20 surveyed institutions around the globe, revealed that, even though slides exclusively hand-painted, and handpainted over printed outlines are present in small amounts 
when compared to slides with other depiction techniques (e.g. chromolithography and photography), they have representativity in these collections. In the Portuguese collections studied, they represent a quarter of the slides held, and 16 of the 20 institutions surveyed have these types of slides under their care.

The apparent state of preservation of 300 slides from CP and MUHNAC collections was achieved with the careful macroscopic observation of each slide and revealed that more than $10 \%$ are highly deteriorated and in urgent need of interventive conservation treatments. In 20 of these slides, a precise assessment of the state of preservation was obtained by complementing the macroscopic observation with the analytical results of their material characterisation, acquired in previous studies. Acknowledging what is happening at a microscopic and molecular level is fundamental. For instance, the eighteenth-century slides showed severe deterioration problems in the painting materials at the macro- and microscopic level (e.g. paint loss, microcracking and discolouration). On the other hand, seven of the nineteenth-century slides demonstrated that although no signs of degradation were observed with the naked eye, the presence of degradation products in the painting was analytically detected, emphasising the extreme importance of implementing preventive conservation measures, such as the control of the environmental conditions of temperature, relative humidity, and light.

The most common degradation problems found include: overall dust and grime; fractures and lacunas in the glass support that in some cases resulted in the complete loss of the image represented; painting deterioration, that frequently results in microcracking, flacking, and lacunas; and fungi or insect damage in the wood frame, and wear and tear of the paper frame that besides being a structural part of the slides may contain valuable information regarding the local and date of production and seller.

This study revealed that, from the materials that usually constitute these artefacts, the glass and painting are the most sensitive and damaged materials. The general overview of slide care practices from other national and international institutions that hold magic lantern slides through the online survey was fundamental to understanding different collections contexts (e.g. number of slides, slides' production periods, most common damage, and storage and display conditions). Caretakers from four institutions explicitly expressed their concern about these collections due to the lack of personnel, dedicated time, and knowledge about magic lantern slides conservation. These problems consequently result, for example, in the absence of systematic cataloguing and digitisation, information about their state of preservation and monitoring, representing severe risks to the safeguard of these collections.

The preventive conservation guidelines presented in this work were developed as a complement to the general conservation standards for heritage collections, specifically for hand-painted magic lantern slide collections. With these recommendations, the authors aim to raise awareness and share more information about these objects, to allow easier identification of degradation problems and factors that can be mitigated and improve the routine care of these collections worldwide.

These guidelines concern the primary steps that should be considered when surveying a collection (e.g. inventory, cataloguing, and digitisation), the environmental conditions recommended for the preservation of these slides (including temperature, $\mathrm{RH}$, light, fine particles and pest control), storage and display conditions and materials, and handling. Other considerations regarding magic lantern demonstrations and recreations of shows without putting original slides at risk were also made available.

The authors acknowledge the need for further investigation on the materials used for the production of hand-painted magic lantern slides (e.g. regarding the binders and printed outlines) and their causes of damage to improve the conservation strategies, particularly concerning the most appropriate materials and procedures for cleaning, consolidation and restoration.

The project in which this work was developed aims to produce reconstructions of paints based on nineteenthcentury paint recipes, to understand their behaviour in adverse environmental conditions. In the future, degradation mechanisms will be studied, and the degraded samples produced in the laboratory will be used to explore different procedures and materials available and establish the best interventive options.

\section{Acknowledgments}

The authors acknowledge the support of the Portuguese Foundation for Science and Technology (FCT-MCTES), through the doctoral program CORES-PD/00253/2012, for the PhD grant PD/BD/136694/2018 (Ângela Santos), and Research Unit VICARTE (UIDB/00729/2020). This research has benefited from the use of the infrastructure PRISC (Portuguese Research Infrastructure of Scientific Collections). The authors are also grateful to all the institutions and individuals that accepted to participate in the online survey, and to the Portuguese Cinematheque - Museum of Cinema, and National Museum of Natural History and Science of the University of Lisbon for the collaboration with the project "Lanterna Magica - Technology and Preservation of Painted Glass Slides for Projection with Magic Lanterns". The authors would also like to acknowledge for the relevant comments of the reviewers that significantly contributed to the improvement of the manuscript.

\section{REFERENCES}

1. Frutos, F. J., 'Un publico encantado. Las proyecciones audiovisuales mediante linterna magica al servicio de la divulgacion cientifica. A thrilled audience: Audiovisual projections using the magic lantern with a view to scientific divulgation', Cultura y Educación 21(3) (2009) 305-318, https:// doi.org/10.1174/113564009789052299.

2. Balzer, R., Optical Amusements: Magic Lanterns and Other Transforming Images. A Catalog of Popular Entertainments, Richard Balzer, Massachusetts (1987). 
3. Robinson, D.; Herbert, S.; Crangle, R. (eds.), Encyclopaedia of the Magic Lantern, The Magic Lantern Society, London (2001).

4. Campagnoni, D. P., 'História da Lanterna Magalográphica vulgarmente dita Lanterna Mágica', in A Magia da Imagem: A Arqueologia do Cinema através das coleções do Museu Nacional de Turim, Centro Cultural de Belém, Lisboa (1996) 59-89.

5. Cochrane, G.; Cowles, C.; Hardman, M.; Holmes, J., Magic Lantern Slide Show, Tasmanian School of Art Gallery, Hobart (1979).

6. Frutos, F. J., 'From Luminous Pictures to Transparent Photographs: The Evolution of Techniques for Making Magic Lantern Slides', The Magic Lantern Gazette 25(3) (2013) 3-11.

7. López San Segundo, C.; Frutos, F. J.; Therón, R., 'Linternauta: a web application for the interpretation of magic lantern slides according to discursive genre', Early Popular Visual Culture 17(3-4) (2019) 361-385, https://doi.org/10.1080/17460654. 2019.1705650.

8. Groom, E., The Art of Transparent Painting on Glass, Winsor and Newton, London (1855).

9. Kember, J., 'The magic lantern: open medium', Early Popular Visual Culture 17(1) (2019) 1-8, https://doi.org/10.1080/17460654 .2019 .1640605 .

10. AMP, 'A Million Pictures: Magic Lantern Slide Heritage as Artefacts in the Common European History of Learning' (2018), https://a-million-pictures.wp.hum.uu.nl (accessed 2018-04-26).

11. Dellmann, S., 'Beyond and with the object: assessing the dissemination range of lantern slides and their imagery', Early Popular Visual Culture 14(4) (2016) 340-358, https://doi.org/10.10 80/17460654.2016.1222927.

12. Santos, Â.; Otero, V.; Rodrigues, B.; Vilarigues, M., 'Unravelling the Secrets of Magic Lantern Slide Painting', The Magic Lantern 22 (2020) 10-12, http://www.magiclantern.org. uk/the-magic-lantern/issue.php?id=4010384 (accessed 202101-12).

13. 'Slides \& Transparencies', in Preservation Self-Assessment Program, University of Illinois at Urbana-Champaign, Illinois, https://psap.library.illinois.edu/collection-id-guide/slide (accessed 2020-03-11).

14. Clark, S., Preservation of photographic material, Preservation Advisory Centre - British Library, London (2009).

15. Hill, G., 'Caring for photographic materials' (2018), in Preventive conservation guidelines for collections, Canadian Conservation Institute, Canada, https://www.-canada.ca/ en/conservation-institute/services/preventive-conservation/ guidelines-collections/photographic-materials.html (accessed 2020-04-07).

16. Santos, Â.; Otero, V.; Vilarigues, M., 'Characterisation of Glass and Painting Materials from 18th-Century Hand-Painted Glass Slides Used for Projection with Magic Lanterns', in Recent Advances in Glass and Ceramics Conservation 2019: Interim Meeting of the ICOM-CC Glass and Ceramics Working Group and Icon Ceramics and Glass Group Conference, ed. J. Mandrus, V. Schussler, London (2019) 223-228.

17. Rodrigues, B.; Santos, Â.; Melo, M. J.; Otero, V.; Vilarigues, M., 'Magic Lantern Glass Slides Materials and Techniques: the First Multi-Analytical Study', Heritage 2(154) (2019) 2513-2530, https://doi.org/10.3390/heritage2030154.
18. Ploeger, R.; Scalarone, D.; Chiantore, O., 'Non-Invasive MidInfrared Fibre Optic Reflectance Spectroscopy Analysis of Painted Glass Magic Lantern Plates', in Art 2008, 9th International Conference on NDT of Art, Jerusalem, Israel (2008).

19. Ploeger, R.; Scalarone, D.; Chiantore, O., 'Non-invasive characterisation of binding media on painted glass magic lantern plates using mid-infrared fibre-optic reflectance spectroscopy', Journal of Cultural Heritage 11(1) (2010) 35-41, https://doi.org/10.1016/j.culher.2009.01.005.

20. Scalarone, D.; Agostino, A.; Chiantore, O.; Basano, R., 'Vetri da proiezione dipinti per lanterne magiche: analisi non invasive di leganti e pigmenti', in Lo Stato dell'Arte 4, IV Congresso Nazionale IGIIC, Nardini Editore, Siena (2006) 63-70.

21. Santos, Â.; Otero, V.; Vilarigues, M., 'Lanterna Magica Technology and Preservation of Painted Glass Slides for Projection with Magic Lanterns' (2018), in Faculdade de Ciências e Tecnologia, Universidade NOVA de Lisboa, https://sites. fct.unl.pt/lanterna_magica/home (accessed 2020-01-02).

22. Rodrigues, A. J., 'The Glass Collection of Ferdinand II in Museu Nacional de Arte Antiga: study and preservation', $\mathrm{PhD}$ dissertation, Department of Conservation and Restoration, NOVA University of Lisbon, Lisbon (2018).

23. Koob, S. P.; van Giffen, N. A. R.; Kunicki-Goldfinger, J. J.; Brill, R. H., 'Caring for Glass Collections: The Importance of Maintaining Environmental Controls', Studies in Conservation 63(sup1) (2018) 146-150, https://doi.org/10.1080/00393630.2018 .1492252.

24. Kunicki-Goldfinger, J. J., 'Unstable historic glass: symptoms, causes, mechanisms and conservation', Studies in Conservation 53(sup2) (2008) 47-60, https://doi.org/10.1179/sic.2008.53. supplement-2.47.

25. Rodrigues, A.; Fearn, S.; Palomar, T.; Vilarigues, M., 'Early stages of surface alteration of soda-rich-silicate glasses in the museum environment', Corrosion Science 143 (2018) 362-375, https://doi.org/10.1016/j.corsci.2018.08.012.

26. Barnes, J., 'Classification of Magic Lantern Slides for Cataloguing and Documentation', in Magic Images: The Art of Hand-Painted and Photographic Lantern Slides, ed. D. Crompton, D. Henry, S. Herbert, The Magic Lantern Society of Great Britain, London (1990) 75-84.

27. Keene, S., Managing Conservation in Museums, 2nd ed., Butterworth-Heinemann, Oxford (2002).

28. 'Condition Reporting - Paintings. Part III: Glossary Canadian Conservation Institute (CCI) Notes 10/11' (2016), in Government of Canada, Canadian Conservation Institute, https://www.canada.ca/en/conservation-institute/services/ conservation-preservation-publications/canadianconservation-institute-notes/condition-reporting-paintingsglossary.html (accessed 2020-02-19).

29. Davison, S., Conservation and Restoration of Glass, 2nd ed., Butterworth-Heinemann, Oxford (2003).

30. Koob, S. P., Conservation and Care of Glass Objects, Archetype Publications and The Corning Museum of Glass, London (2006).

31. Boylan, P. J. (ed.), Running a Museum: A Practical Handbook, ICOM - International Council of Museums, Paris (2004).

32. 'Preventive conservation guidelines for collections' (2018), in Gonvernment of Canada, https://www.canada.ca/en/ 
conservation-institute/services/preventive-conservation/ guidelines-collections.html (accessed 2019-05-15).

33. Atkinson, J. K., 'Environmental conditions for the safeguarding of collections: A background to the current debate on the control of relative humidity and temperature', Studies in Conservation 59(4) (2014) 205-212, https://doi.org/10.11 79/2047058414Y.0000000141.

34. Brown, S.; Cole, I.; Daniel, V.; King, S.; Pearson, C. (eds.), Guidelines for Environmental Control of Cultural Institutions, Heritage Collections Council, Camberra (2002).

35. The National Trust, The National Trust Manual of Housekeeping, Butterworth-Heinemann, Oxford (2006).

36. Bacharach, J., 'Museums Collections Environment', in The Museum Handbook. Part I: Museum Collections, National Park Service, Washington (2016) 4:1-4:56.

37. Duyck, E., 'Museum Collection Storage', in The Museum Handbook. Part I: Museum Collections, National Park Service, Washington (2012) 7:1-7:26.

38. Lucerna CIC, LUCERNA - the Magic Lantern Web Resource, http://lucerna.exeter.ac.uk (accessed 2018-05-27).

39. Lenk, S.; Crangle, R.; Dellmann, S.; Frutos, J.; Kember, J.; Napp, A.; Fernández, D.; Doren, I.;Vogl-Bienek, L., 'How to digitise slides. Recommendations and working lists for the reproduction of a very special artefact' (2018), in Utrecht University, https://a-million-pictures-recommendations. wp.hum.uu.nl (accessed 2019-02-15).

40. Coccato, A.; Moens, L.; Vandenabeele, P., 'On the stability of mediaeval inorganic pigments: a literature review of the effect of climate, material selection, biological activity, analysis and conservation treatments', Heritage Science 5(1) (2017) 1-25, https://doi.org/10.1186/s40494-017-0125-6.
41. Clark, D. E. and Zoitos, B. K., Corrosion of Glass, Ceramics and Ceramic Superconductors, Noyes Publications (1992).

42. Corrêa Pinto, A. M.; Palomar, T.; Alves, L. C.; da Silva, S. H. M.; Monteiro, R. C.; Macedo, M. F.; Vilarigues, M. G., 'Fungal biodeterioration of stained-glass windows in monuments from Belém do Pará (Brazil)', International Biodeterioration and Biodegradation 138 (2019) 106-113, https://doi.org/10.1016/j. ibiod.2019.01.008.

43. Navarro, J. M. F., El vidrio, Consejo Superior de Investigaciones Científicas. Sociedad Española de Cerámica y Vidrio, Madrid (2003).

44. Tétreault, J., Airborne pollutants in museums, galleries, and archives: risk assessment, control strategies, and preservation management, Canadian Conservation Institute, Ottawa (2003).

45. Robinet, L.; Hall, C.; Eremin, K.; Fearn, S.; Tate, J., 'Alteration of soda silicate glasses by organic pollutants in museums: Mechanisms and kinetics', Journal of Non-Crystalline Solids 355(28-30) (2009) 1479-1488, https://doi.org/10.1016/j. jnoncrysol.2009.05.011.

RECEIVED: 2020.5 .29

REVISED: 2020.12 .11

ACCEPTED: 2020.12.22

ONLINE: 2021.1.25

\section{(c) (1) (3)}

This work is licensed under the Creative Commons Attribution-NonCommercial-NoDerivatives 4.0 International License. To view a copy of this license, visit http://creativecommons.org/licenses/by-nc-nd/4.o/deed.en. 